\title{
Lrp4 in hippocampal astrocytes serves as a negative feedback factor in seizures
}

\author{
Zheng Yu ${ }^{1,2}$, Meiying Zhang ${ }^{3}$, Bin Luo ${ }^{2}$, Hongyang Jing ${ }^{2}$, Yue Yu ${ }^{4}$, Shunqi Wang ${ }^{2}$ and Shiwen Luo $1,5^{*}$
}

\begin{abstract}
Background: Epilepsy is characterized by the typical symptom of seizure, and anti-seizure medications are the main therapeutic method in clinical, but the effects of these therapy have not been satisfactory. To find a better treatment, it makes sense to further explore the regulatory mechanisms of seizures at genetic level. Lrp4 regionally expresses in mice hippocampus where is key to limbic epileptogenesis. It is well known that neurons release a high level of glutamate during seizures, and it has been reported that Lrp4 in astrocytes down-regulates glutamate released from neurons. However, it is still unclear whether there is a relationship between Lrp4 expression level and seizures, and whether Lrp4 plays a role in seizures.

Results: We found that seizures induced by pilocarpine decreased Lrp4 expression level and increased miR-351-5p expression level in mice hippocampus. Glutamate reduced Lrp4 expression and enhanced miR-351-5p expression in cultured hippocampal astrocytes, and these effects can be partially attenuated by AP5. Furthermore, miR-351-5p inhibitor lessened the reduction of Lrp4 expression in glutamate treated hippocampal astrocytes. Local reduction of Lrp4 in hippocampus by sh Lrp4 lentivirus injection in hippocampus increased the threshold of seizures in pilocarpine or pentylenetetrazol (PTZ) injected mice.

Conclusions: These results indicated that high released glutamate induced by seizures down-regulated astrocytic Lrp4 through increasing miR-351-5p in hippocampal astrocytes via activating astrocytic NMDA receptor, and locally reduction of Lrp4 in hippocampus increased the threshold of seizures. Lrp4 in hippocampal astrocytes appears to serve as a negative feedback factor in seizures. This provides a new potential therapeutic target for seizures regulation.
\end{abstract}

Keywords: Low-density lipoprotein receptor-related protein 4, Epilepsy, microRNA, Astrocytic NMDA receptor, The threshold of seizure

\section{Background}

Epilepsy is one of the most neurological diseases, which affects over 50 million people worldwide [1]. The definition of Epilepsy is a disorder of the brain characterized by an enduring predisposition to generate epileptic seizures. In the clinical, it is usually practically applied as having two unprovoked seizures $>24 \mathrm{~h}$ apart [2]. The main goal of treatment for epilepsy is to stop seizures, reduce morbidity and decrease the risk of premature mortality

\footnotetext{
*Correspondence: shiwenluo@ncu.edu.cn

${ }^{1}$ Center for Experimental Medicine, The First Affiliated Hospital of Nanchang University, Nanchang 330006, Jiangxi, China

Full list of author information is available at the end of the article
}

associated with continuing seizures [3]. Although over 25 anti-seizure medications are currently used in clinical, only about $66 \%$ patients respond to these drug [4]. In reality, more than half of those taking epilepsy medication were still having seizures [5]. So, it is important to explore new anti-seizure methods. To achieve this goal, it makes sense to explore the regulatory mechanisms of seizures at genetic level.

Lrp4 is a type I single transmembrane protein of the LDLR family with a large extracellular domain, which expresses widely in many organs of mice, such as muscles [6], brain [7, 8], bone [9-11], mammary and other skin appendage placodes [12], and kidney [13]. In muscle,

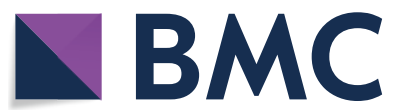

(c) The Author(s) 2020. This article is licensed under a Creative Commons Attribution 4.0 International License, which permits use, sharing, adaptation, distribution and reproduction in any medium or format, as long as you give appropriate credit to the original author(s) and the source, provide a link to the Creative Commons licence, and indicate if changes were made. The images or other third party material in this article are included in the article's Creative Commons licence, unless indicated otherwise in a credit line to the material. If material is not included in the article's Creative Commons licence and your intended use is not permitted by statutory regulation or exceeds the permitted use, you will need to obtain permission directly from the copyright holder. To view a copy of this licence, visit http://creativeco mmons.org/licenses/by/4.0/. The Creative Commons Public Domain Dedication waiver (http://creativecommons.org/publicdomain/ zero/1.0/) applies to the data made available in this article, unless otherwise stated in a credit line to the data. 
Lrp4 mainly expresses in the neuromuscular junction (NMJ) where is the site for the transmission of action potential from nerve to the muscle. Lrp4 serves as a receptor for AGRIN and is critical for the formation and maintenance of the NMJ [14]. In brain, Lrp4 regionally expresses in hippocampal astrocytes, and astrocytic Lrp4 maintains glutamatergic transmission by controlling the release of ATP from astrocytes. Hippocampus is an area where is key importance for limbic epileptogenesis, and GFAP-Lrp $4^{-1-}$ mice had a raised threshold to seizures [7, 8]. So, the question here is whether there is a relationship between Lrp4 expression and seizures, and whether Lrp4 plays a role in seizures.

Animal seizures model has been widely employed to evaluate the progression of seizures, and used to study how seizures regulate gene expression in brain $[15,16]$. It has been reported that pilocarpine treated rodents provokes a rapid and prolonged seizure, and leads to several molecular and cellular changes in hippocampus [17, 18]. We found that high released glutamate in seizures induced by pilocarpine down-regulated astrocytic Lrp4 expression through increasing miR-351-5p expression level in hippocampal astrocytes via activating astrocytic NMDA receptor. Furthermore, the local reduction of Lrp4 induced by sh Lrp4 lentivirus injection in mice hippocampus increased the threshold of seizures in pilocarpine or pentylenetetrazol (PTZ) injected mice.

\section{Results}

Seizures induced by pilocarpine decreased Lrp4 expression in hippocampus in vivo

To find out whether seizures could influence Lrp4 expression in hippocampal astrocytes, epileptic seizures were induced in adult mouse by pilocarpine injection (300 mg/kg, i.p.) [19]. Under our conditions, discontinuous seizures began to develop at around 20 min after the injection and lasted up to $4 \mathrm{~h}$. Pilocarpine injected mice and controls (saline injected) were sacrificed at different time $0 \mathrm{~h}, 2 \mathrm{~h}, 4 \mathrm{~h}, 12 \mathrm{~h}$ after injection (each time point, $\mathrm{n}=3$, per group), and total mRNAs of hippocampus were isolated for RT-qPCR. The results showed that seizures induced by pilocarpine significantly increased the relative level of $B d n f$ mRNA in hippocampus at each time point after injection, compared to control mice (injected with saline) (Additional file 1: Fig. S1A), which is in agreement with previous observations [20,21]. This result indicated that pilocarpine induced seizures regulated gene expression in hippocampus. Intriguingly, compared to control mice, the relative level of Lrp 4 mRNA in hippocampus was significantly decreased in pilocarpine injected mice. After injection, relative Lrp 4 mRNA level began to decrease at $2 \mathrm{~h}$ and move on to $12 \mathrm{~h}$ with further reduction (Fig. 1a). To confirm this result, we used Lrp4-lacZ/+ heterozygote mice $[7,8]$, in which the $\operatorname{Lrp} 4$ gene was replaced with a cassette encoding a $\beta$-galactosidase $(\beta$-gal) fusion protein on one chromosome, to proceed pilocarpine induced seizure experiment. $4 \mathrm{~h}$ after pilocarpine injection, mice were sacrificed and brain slices were stained by X-gal. The results showed that $\beta$-gal activity was significantly reduced in stratum lacunosummoleculare layer $(\mathrm{LMol})$ and molecules layer $(\mathrm{Mol})$ of the hippocampus (most of them are astrocytes), compared to control mice (Fig. 1b). This result also indicated that seizures induced by pilocarpine significantly decreased $\operatorname{Lrp} 4$ mRNA level in hippocampal astrocytes. Furthermore, after injected pilocarpine, total proteins of hippocampus were extracted at different times by RIPA and resolved by SDS-PAGE and subjected to Western blot analysis. The results showed that the relative level of Lrp4 protein in hippocampus were also significantly decreased in pilocarpine injected mice, but it began at $4 \mathrm{~h}$, later than the time of the reduction of Lrp 4 mRNA level (Fig. 1c, d). These results indicated that seizures induced by pilocarpine significantly decreased Lrp4 expression level (both mRNA and protein) in hippocampus in vivo.

\section{Glutamate decreased Lrp4 expression of hippocampal astrocytes in vitro}

To better investigate the mechanism of previous finding, we tried to find a way to mimic pilocarpine induced seizures in vitro. Firstly, primary cultured hippocampal astrocytes were used in our study, because most of Lrp4 expresses in astrocytes $[7,8]$. Then, glutamate $(0.5 \mathrm{mM})$ treatment in cultured hippocampal astrocytes was used, because it has been reported that pilocarpine induces an elevation in glutamate levels in the hippocampus, following the appearance of pilocarpine induced seizures [22], and the increase in the glutamate efflux was found in hippocampal synaptosomes [23], the increase of glutamate release influences gene expression level in astrocytes [24]. $4 \mathrm{~h}$ after glutamate treatment, total mRNAs of cultured hippocampal astrocytes were isolated for RT-qPCR. The result showed that the relative level of $B d n f$ mRNA in glutamate treated astrocytes significantly increased, compared to control (vehicle treatment) (Additional file 1: Fig $\mathrm{S} 1 \mathrm{~B})$. The result was in agreement with previous report [24] and our previous data in vivo (Fig. 1a). This indicated that glutamate can be used to treat cultured hippocampal astrocytes to mimic the process that pilocarpine induced seizures influences gene expression level in hippocampal astrocytes in vivo. To detect whether Lrp4 mRNA level in cultured hippocampal astrocytes could be changed by glutamate, mRNA was collected at different times after glutamate treatment. The result showed that the relative mRNA level of Lrp 4 began to decrease about 30\% at $2 \mathrm{~h}$, and about $60 \%$ at $12 \mathrm{~h}$ (Fig. 2a). At the protein level, 


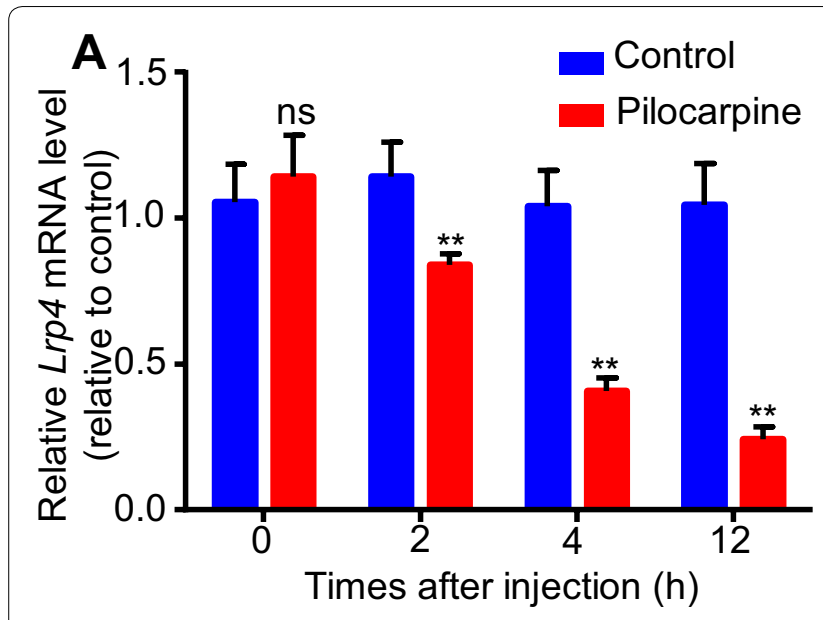

C

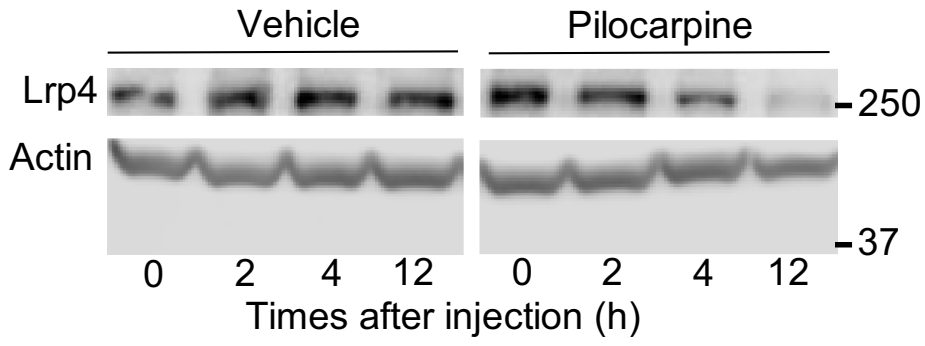

B
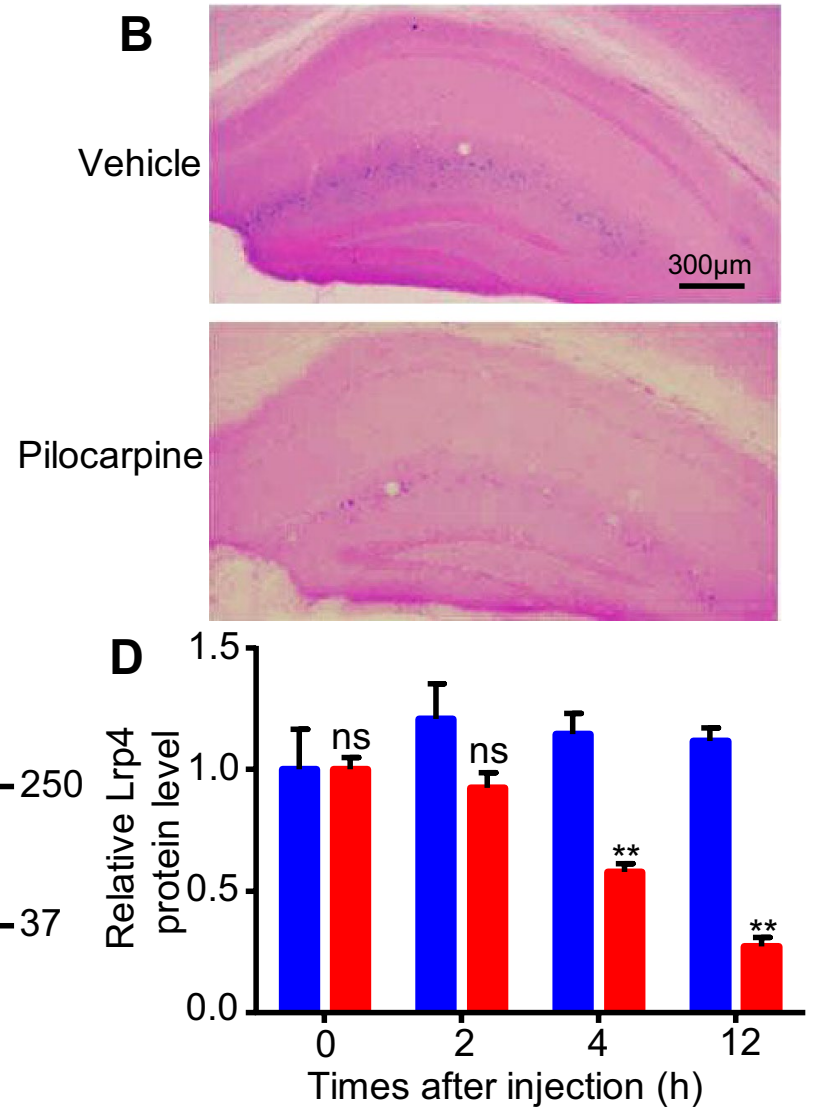

Fig. 1 Seizures induced by pilocarpine decreased Lrp4 expression in mice hippocampus. a Relative mRNA level of $L$ rp4 in the hippocampus of pilocarpine injected mice, which were collected at different time point $(0 \mathrm{~h}, 2 \mathrm{~h}, 4 \mathrm{~h}, 12 \mathrm{~h}$ ) after injection. Comparing to control mice (vehicle injection), Lrp4 mRNA decreased after injection ( 2 h, 4 h, 12 h). b X-gal staining the brain slice of pilocarpine injected Lrp4-lacZ/+ mice. $\beta$-Gal activity decreased in both stratum lacunosum-moleculare layer (LMol) and molecules layer (Mol) of hippocampus. $\mathbf{c}$ Lrp4 protein level in the hippocampus of pilocarpine injected mice, which were collected at different time point $(0 \mathrm{~h}, 2 \mathrm{~h}, 4 \mathrm{~h}, 12 \mathrm{~h})$ after injection, Actin as an internal control. $\mathbf{d}$ Quantification of Lrp4 protein level in c, Lrp4 protein decreased after injection ( $4 \mathrm{~h}, 12 \mathrm{~h}$ ). For each experiment, three separate experiments were performed in duplicate $\left.{ }^{* *} \mathrm{p}<0.01\right)$

the relative level of Lrp4 protein in hippocampal astrocytes has no significantly changes at $2 \mathrm{~h}$ after glutamate treatment, but began to decrease $30 \%$ at $4 \mathrm{~h}$ and then decreased $50 \%$ at $12 \mathrm{~h}$ (Fig. 2b, c). These results indicated that glutamate decreased the Lrp4 expression level in cultured hippocampal astrocytes.

\section{Glutamate decreased Lrp4 expression in cultured hippocampal astrocytes through activating astrocytic NMDA receptor}

To investigate the mechanism of the reduction of Lrp4 expression in glutamate treated hippocampal astrocytes, cultured hippocampal astrocytes were treated with glutamate $(0.5 \mathrm{mM})$ with or without AP5 $(50 \mathrm{mM})$ simultaneously. After $12 \mathrm{~h}$, compared to control, the relative level of Lrp4 mRNA decreased about 70\% in astrocytes which were treated by glutamate without AP5, but only decreased about $20 \%$ in astrocytes which were treated by glutamate with AP5 (Fig. 2d). We also detected the change of Lrp4 protein level in this assay. After $12 \mathrm{~h}$, the reduction of Lrp4 protein in glutamate with AP5 treated hippocampal astrocytes was also less than that in glutamate without AP5 treated hippocampal astrocytes (Fig. 2e, f). These results showed that NMDA receptor antagonist AP5 can partially attenuated the reduction of Lrp4 mRNA and Lrp4 protein expression level in glutamate treated astrocytes. This indicated that glutamate decreased Lrp4 expression in cultured hippocampal astrocytes through activating astrocytic NMDA receptor.

\section{Seizures induced by pilocarpine increased miR-351-5p expression in mice hippocampus in vivo}

MicroRNAs play important gene-regulatory roles in animals and direct their posttranscriptional repression 


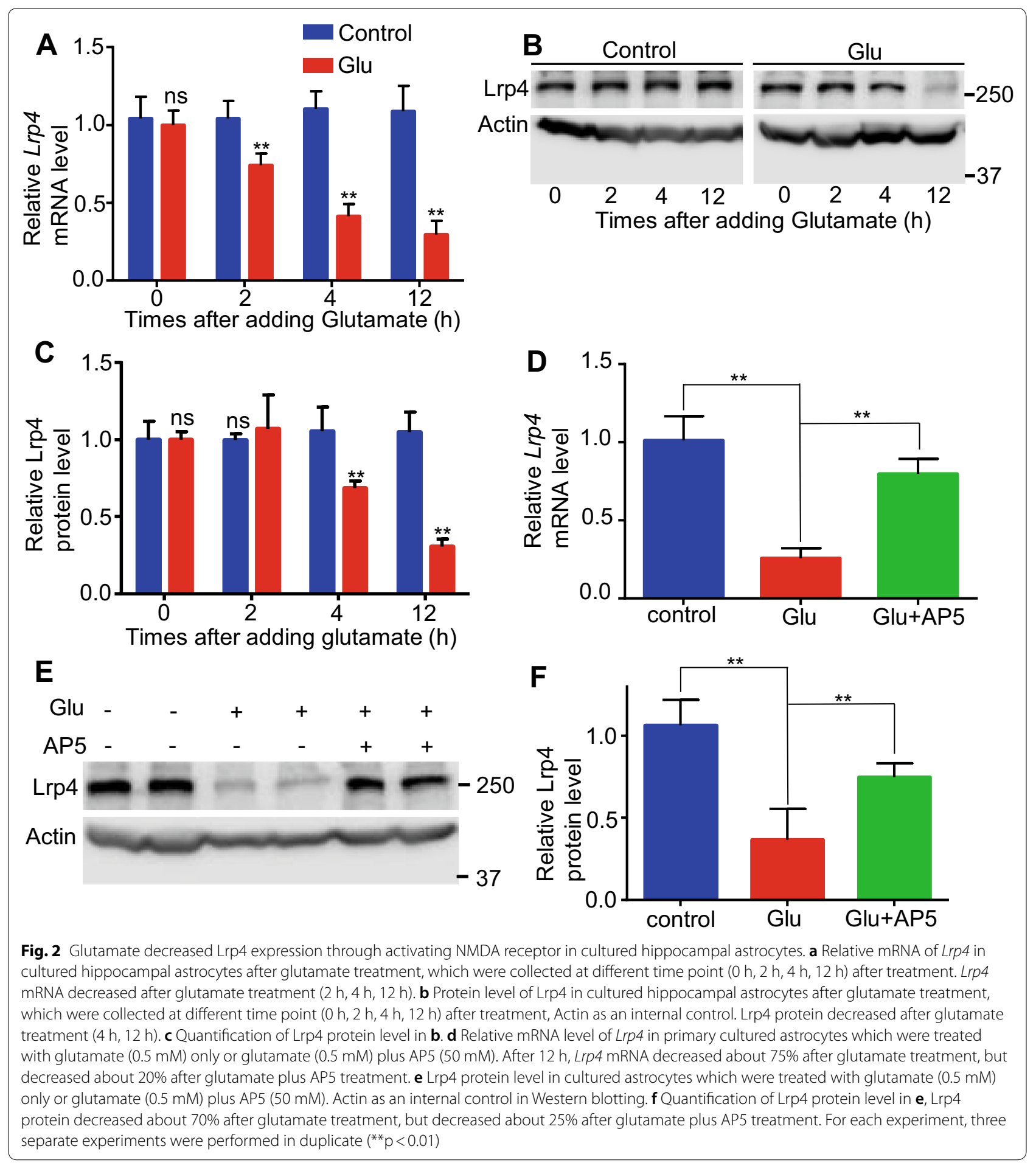

by pairing to the mRNAs of protein-coding genes [25]. TargetScan website is the most widely used website for predicting microRNAs to regulate protein expression [26]. Through this website's query, we found top 5 predict microRNA which target to mouse Lrp4 gene:
mmu-miR-125a-5p, mmu-miR-125b-5p, mmu-miR351-5p, mmu-miR-6367, mmu-miR-6394. Then we detected whether seizures induced by pilocarpine could regulate the expression of these 5 microRNAs in mice hippocampus. After $4 \mathrm{~h}$ injection of pilocarpine or saline 
(vehicle control), mice were sacrificed, and total RNAs of hippocampus were isolated and stem-loop microRNA RT-qPCR assay was used to analyze microRNA. Quantitation cycle $(\mathrm{Cq})$ values of microRNA were normalized to U6 small nuclear RNA, which was used as an internal control. The result showed that pilocarpine only significantly increased the relative level of mmu-miR351-5p in hippocampus, but not those of mmu-miR125a-5p, mmu-miR-125b-5p, mmu-miR-351-5p, and mmu-miR-6367 (Fig. 3a). These results were consistent with previous report [27]. Then we detected the increase of mmu-miR-351-5p level in hippocampus induced by seizures at different times. The result showed that compared to control, mmu-miR-351-5p expression began to increase around 6 times at $2 \mathrm{~h}$ after pilocarpine injection, and the elevation persisted for more than $12 \mathrm{~h}$ (Fig. 3b), which were simultaneous with the reduction of Lrp4 expression in hippocampus. These results indicated that seizures induced by pilocarpine increased mmu-miR351-5p level in mice hippocampus.

\section{Glutamate increased mmu-miR-351-5p level in cultured hippocampal astrocytes through activating astrocytic NMDA receptor in vitro}

Again, we wanted to detect whether glutamate can increase mmu-miR-351-5p expression in cultured hippocampal astrocytes. After treated with glutamate $(0.5 \mathrm{mM})$, mmu-miR-351-5p level in cultured

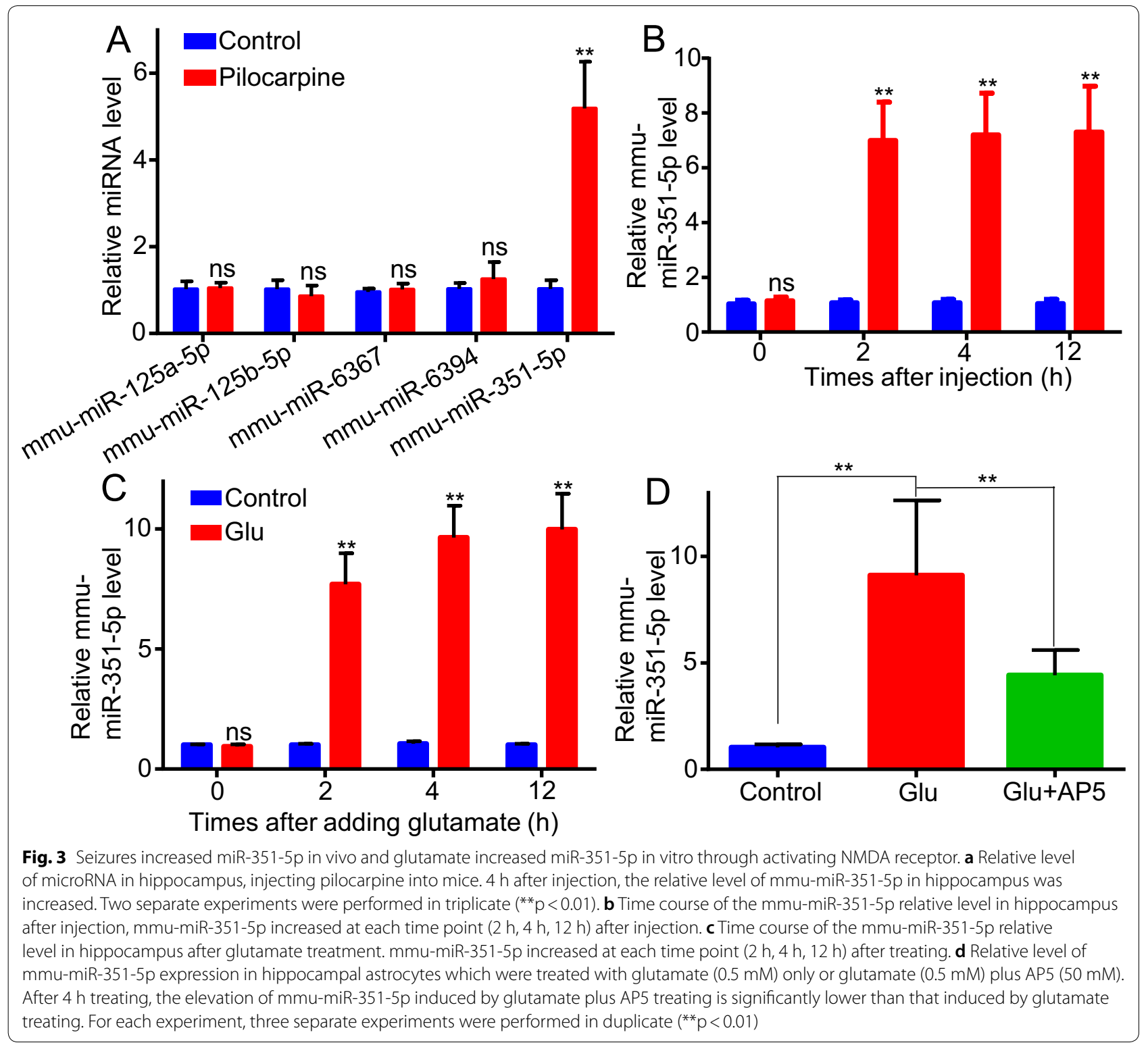


hippocampal astrocytes was increased about 7 times at $2 \mathrm{~h}$ after glutamate treatment, and the elevation persisted for more than $12 \mathrm{~h}$ (Fig. 3c), which was consistent with previous data in vivo. Furthermore, cultured hippocampal astrocytes were treated with glutamate $(0.5 \mathrm{mM})$ without or with AP5 $(50 \mathrm{mM})$ at the same time. After $12 \mathrm{~h}$, total RNAs of astrocytes were isolated for micro RNA RT-qPCR. The results showed that the elevation of mmu-miR-351-5p level in glutamate with AP5 treated astrocytes is significant lower than that in glutamate without AP5 treated astrocytes (Fig. 3d). These results indicated that glutamate increased the expression of mmu-miR-351-5p in cultured hippocampal astrocytes through activating astrocytic NMDA receptor.

\section{miR-351-5p mimics decreased Lrp4 expression in cultured hippocampal astrocytes in vitro}

Previous data showed that seizures or glutamate increased miR-351-5p and reduced Lrp4 concurrently in hippocampal astrocytes in vivo or in vitro. The question is whether the reduction of Lrp4 level is due to the increasing of miR-351-5p level in hippocampal astrocytes. To answer this question, cultured hippocampal astrocytes were transfected respectively with miR351-5p mimics or miR-351-5p m NC (control mimics) (50 nM). After $24 \mathrm{~h}$, the miR-351-5p level significantly increased in miR-351-5p mimics transfected astrocytes compared to control (not transfected astrocytes), but no change in miR-351-5p m NC transfected astrocytes. The results showed that miR-351-5p level was successfully increased in miR-351-5p mimics transfected hippocampal astrocytes (Fig. 4a). Then different concentration of miR-351-5p mimics (0 nM, $25 \mathrm{nM}, 50 \mathrm{nM}, 100 \mathrm{nM}$ ) were transfected into cultured hippocampal astrocytes. After $24 \mathrm{~h}$, the relative level of $\operatorname{Lrp} 4 \mathrm{mRNA}$ were measured by qPCR. The result showed that the relative level of $\operatorname{Lrp} 4$ mRNA was decreased at each concentration level (25 nM, 50 nM, 100 nM) (Fig. 4b). Because the reduction of relative $\operatorname{Lrp} 4 \mathrm{mRNA}$ had reached about $70 \%$ in $50 \mathrm{nM}$ miR-351-5p mimics treatment astrocytes, we decided to transfect $50 \mathrm{nM}$ miR-351-5p mimics or miR-351-5p $\mathrm{m} \mathrm{NC}$ into cultured hippocampal astrocytes to do next experiments. After transfected by miR-351-5p mimics, the relative Lrp4 protein level in cultured hippocampal astrocytes was significantly decreased compared to control, but no change in miR-351-5p m NC transfected astrocytes (Fig. 4c, d). These results indicated that Lrp4 expression level in cultured hippocampal astrocytes could be suppressed by miR-351-5p mimics transfection.

\section{miR-351 inhibitors attenuated Lrp4 expression reduction induced by glutamate in cultured hippocampal astrocytes} To further confirm that the reduction of Lrp4 expression level in astrocytes is due to the increasing of miR-351-5p, cultured hippocampal astrocytes were transfected with miR-351-5p inhibitors or miR-351-5p I NC (control inhibitors) (50 $\mathrm{nM}$ respectively). After $24 \mathrm{~h}$, the miR-351-5p level significantly decreased in miR-351-5p inhibitors transfected astrocytes compared to control (not transfected astrocytes), but there was no change in miR-351-5p I NC transfected astrocytes (Fig. 4a). The result indicated that miR-351-5p expression in hippocampal astrocytes can be successfully suppressed by miR-351-5p inhibitors. Then we transfected miR-351-5p inhibitors or miR-351-5p I NC (50 $\mathrm{nM}$ respectively) into cultured hippocampal astrocytes. After $24 \mathrm{~h}$, astrocytes were treated with glutamate (50 $\mathrm{mM}$ ) for $4 \mathrm{~h}$. The mRNA or protein were collected and subjected to qPCR or western blot. The results showed that compared to control astrocytes, both the relative level of Lrp 4 mRNA and Lrp4 protein decreased about 75\% in the glutamate treated astrocytes and glutamate treated with miR-351-5p miR-351-5p I NC transfected astrocytes,

\footnotetext{
(See figure on next page.)

Fig. 4 miR-351-5p inhibitor attenuated the reduction of Lrp4 expression by glutamate treating in cultured hippocampal astrocytes. a Relative level of mmu-miR-351-5p in hippocampal astrocytes which were transfected respectively by miR-351-5p mimics, miR-351-5p m NC (mimics negative control), miR-351-5p inhibitor, miR-351-5p I NC (inhibitors negative control). miR-351-5p mimics enhanced the miR-351-5p level and miR-351-5p inhibitors weakened the miR-351-5p level. b Relative level of Lrp4 mRNA in primary cultured hippocampal astrocytes which were transfected with miR-351-5p mimics at different concentration (0 nM, $25 \mathrm{nM}, 50 \mathrm{nM}, 100 \mathrm{nM})$. Lrp4 mRNA level decreased at the test concentration of the mimics (25 nM, 50 nM, 100 nM). c Lrp4 protein level in cultured astrocytes after transfecting miR-351-5p mimics by Western blotting. Action as an internal control. d Quantification of Lrp4 protein level from panel C, miR-351-5p mimics cut down Lrp4 protein expression. e mRNA level of Lrp4 in astrocytes after glutamate treatment only or glutamate treatment plus miR-351-5p inhibitors transfection. mRNA level of Lrp4 in astrocytes decreased about $70 \%$ by glutamate treating, and decreased about 25\% by glutamate plus miR-351-5p inhibitors treating. f Lrp4 protein level in cultured astrocytes after glutamate treatment only or glutamate treatment plus miR-351-5p inhibitors transfection, Actin as an internal control. $\mathbf{g}$ Quantification of Lrp4 protein level from f, Lrp4 protein in astrocytes decreased about 70\% by glutamate treating and decreased about $25 \%$ by glutamate plus miR-351-5p inhibitors treating. For each experiment, three separate experiments were performed in duplicate $\left.{ }^{* *} \mathrm{p}<0.01\right)$
} 


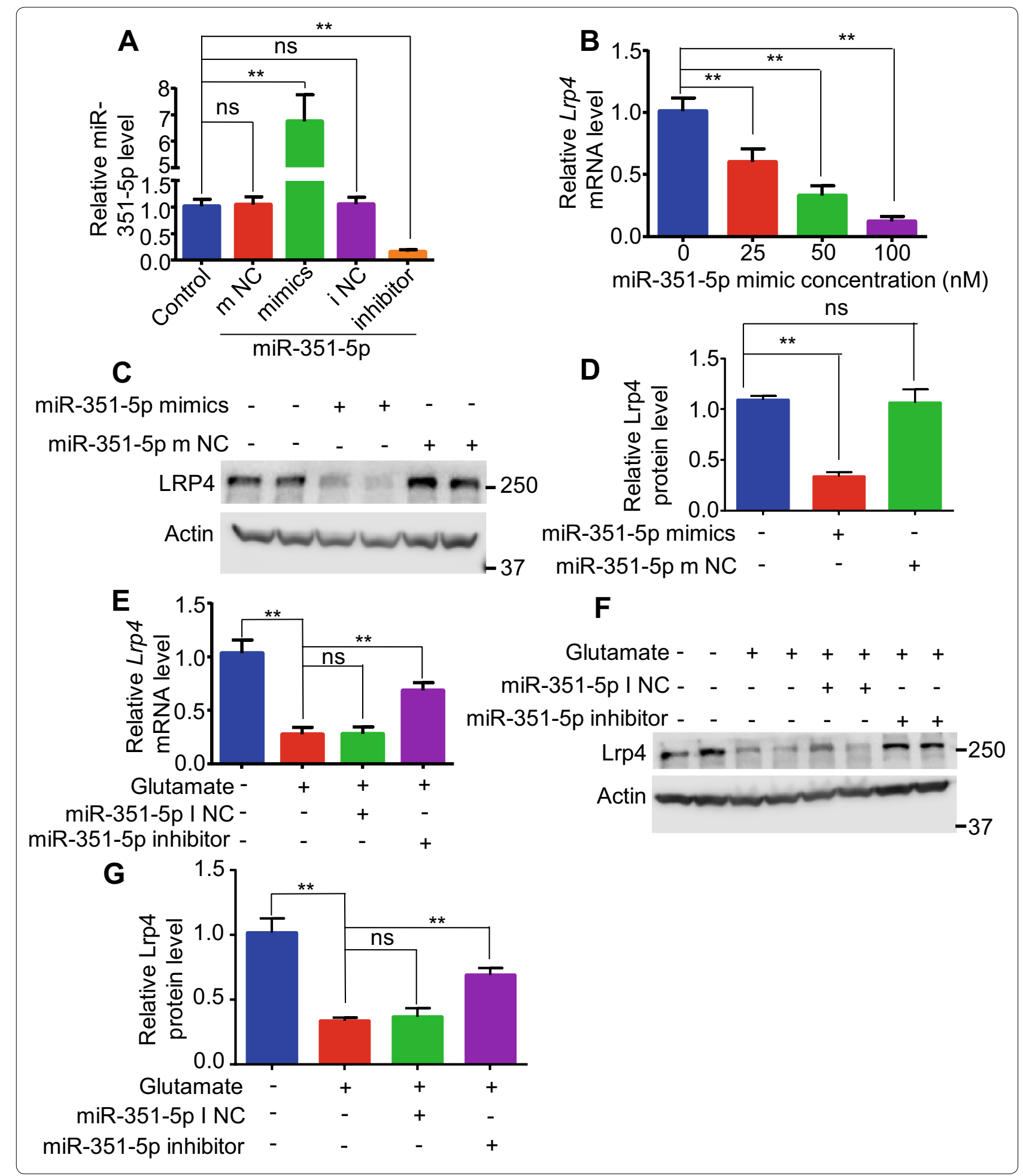

but only decreased about $25 \%$ in glutamate treated with miR-351-5p inhibitors transfected astrocytes (Fig. 4e-g). These results showed that miR-351-5p inhibitors attenuated the reduction of Lrp4 expression level in glutamate treated hippocampal astrocytes. Combine with previous data, it was proven that the reduction of Lrp4 expression level in glutamate treated hippocampal astrocytes was caused by the increase of mmu-miR-351-5p. 
Low expression of Lrp4 in the hippocampus of mice trans-infected by sh Lrp4 lentivirus enhanced the threshold of seizure

Could the reduction of Lrp4 expression level suppress seizures? We stereotactic injected shRNA lentivirus (sh control, sh Lrp4 scramble, sh Lrp4) into lacunosummoleculare layer (LMol) and molecules layer (Mol) regions of mice hippocampus (Fig. 5a). The mice were allowed to recover for 14 days. Total proteins of hippocampus were extracted by RIPA and resolved by SDS-PAGE and subjected to Western blot analysis. The result showed that sh $\operatorname{Lrp} 4$ lentivirus trans-infection significantly decreased the relative Lrp4 protein level in mice hippocampus, compared to control (sh control

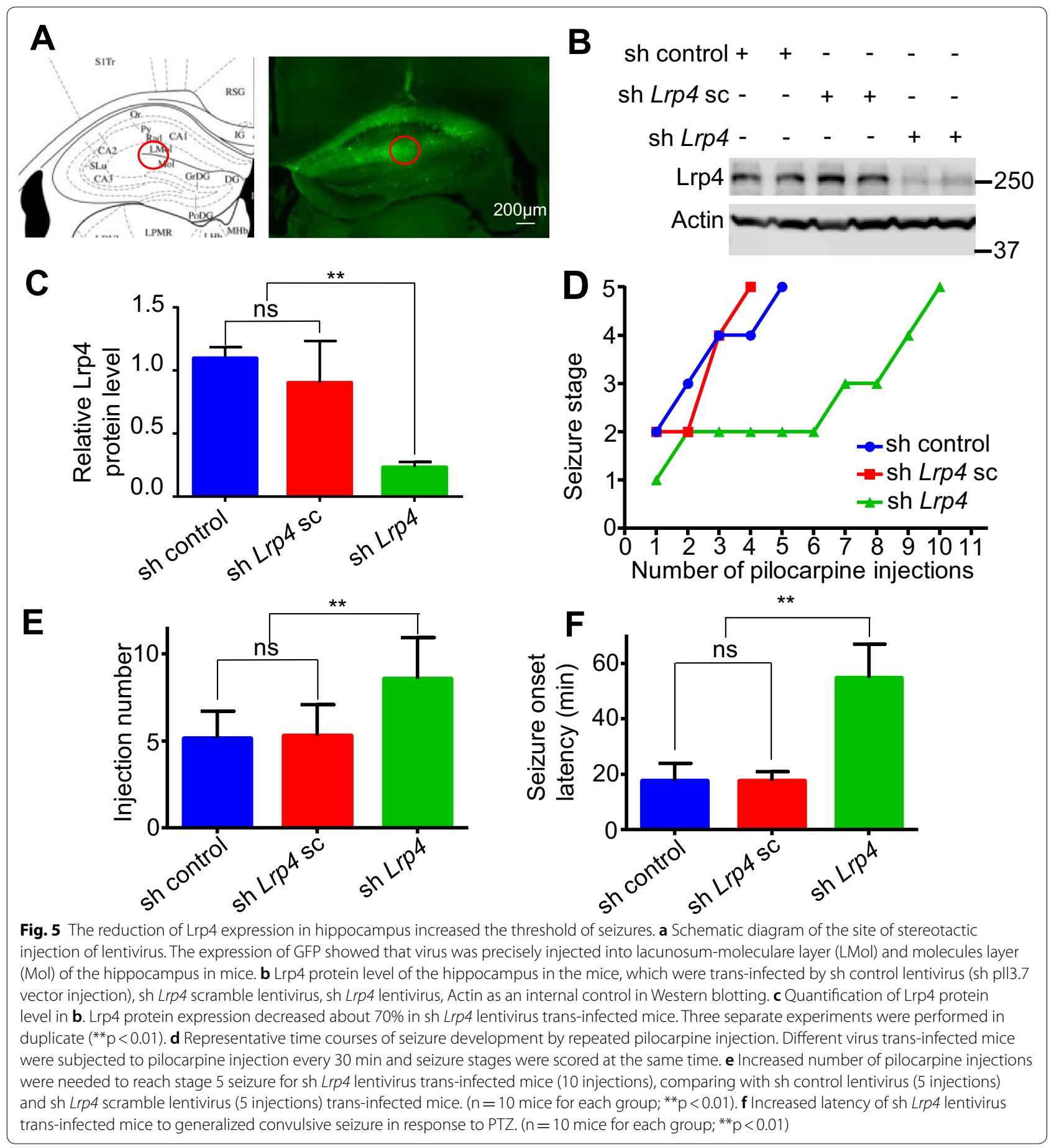


lentivirus injection), but not sh $\operatorname{Lrp} 4$ scramble lentivirus trans-infection. The results indicated the effectiveness of sh Lrp4 (decreasing Lrp4 expression level) (Fig. 5b, c). 2 weeks after lentivirus injection for recovery, we injected mice with pilocarpine $(200 \mathrm{mg} / \mathrm{kg}$, i.p.), and followed additional injections of pilocarpine $(100 \mathrm{mg} / \mathrm{kg})$ every $30 \mathrm{~min}$. Most control mice (sh control lentivirus trans-infected mice) and sh Lrp 4 scramble lentivirus trans-infected mice developed status epilepticus to score 5 (violent convulsions, falling over, death) after the fifth injection. In contrast, a majority of sh Lrp4 lentivirus trans-infected mice did not develop status epilepticus to score 5 even after the ninth injection (Fig. 5d, e). These data indicated that sh Lrp4 lentivirus trans-infected mice had a raised threshold to seizure due to reduction of Lrp4 in hippocampus. After injecting mice with PTZ, a GABAA receptor antagonist that induces seizure via different mechanisms from pilocarpine, we get the same results. The latency to the onset of generalized convulsive seizures (GS) was higher in sh Lrp4 lentivirus trans-infected mice than in control mice (Fig. 5f). These results indicated that the threshold of seizures was upregulated by the reduction of Lrp4 in hippocampus.

\section{Discussion}

Lrp4 is critical in the development and plasticity of synapses, and also in some kinds of nerve system diseases such as MG $[28,29]$. Our results identified that Lrp4 also played a significant role in seizures regulation. Firstly, we found that Lrp4 expression level (both mRNA and protein) significantly decreased in the hippocampus of pilocarpine treated seizures mice (Fig. 1), and glutamate treatment reduced the Lrp4 expression level in cultured hippocampal astrocytes (Fig. 2a-c), which could be partially attenuated by NMDA receptor antagonist AP5 (Fig. 2d-f). Furthermore, we found that seizures induced by pilocarpine increased mmu-miR-351-5p expression level in vivo, and glutamate increased mmu-miR-351-5p expression level in cultured hippocampal astrocytes in vitro (Fig. 3b, c), which also could be partially attenuated by NMDA receptor antagonist AP5 (Fig. 3d). After treated hippocampal astrocytes with miR-351-5p mimics, Lrp4 expression level decreased (Fig. 4b-d). We also found that miR-351-5p inhibitors attenuated glutamate induced Lrp4 expression reduction in cultured hippocampal astrocytes (Fig. $4 \mathrm{e}-\mathrm{g}$ ). These results indicated that increasing glutamate during seizures induced by pilocarpine increased miR-351-5p expression in hippocampal astrocytes via activating astrocytic NMDA receptor, then decreased Lrp4 expression level in hippocampal astrocytes. At last, we stereotactic injected sh Lrp4 lentivirus into mouse hippocampus to decrease
LPR4 expression level in hippocampus (Fig. 5a-c), and found that the threshold of seizures of mice was upregulated (Fig. 5d-f). Together, these results indicated that high released glutamate during pilocarpine induced seizures decreased Lrp4 expression level in hippocampal astrocytes by increasing miR-351-5p in hippocampal astrocytes via activating astrocytic NMDA receptor, and the reduction of Lrp4 expression in hippocampus increased mice seizures threshold.

Seizure is a process result from an imbalance between excitatory and inhibitory activity within a neuronal network [30]. Many different neurobiological dysfunction contributes to this process, such as: neurogenesis [31], proinflammatory processes (interleukin $1 \beta$, TGF $\beta$ ) [32, 33 ], neuronal voltage and ligand gated ion channels [34], neurotransmitter release or uptake [35], intracellular signaling cascades (BDNF, Trk, mTOR) [36-39], astrocytes and microglia [40]. Among them, a growing body of evidence supports that neuron-astrocytes interaction plays a very important role. Previous studies have revealed that adenosine level is rapidly upregulated as an acute response to SE, thus enhancing the protective functions of the adenosine system via increased activation of A1Rs [41]. Furthermore, the reduction of Lrp4 expression in GFAP-Lrp4 $4^{-1-}$ mice elevated the releasement of ATP from hippocampal astrocytes, which increased the threshold of seizures via increased activation of A1Rs by adenosine (a product of ATP hydrolysis) [7, 8]. We found that seizures induced by pilocarpine increased miR-351-5p expression in hippocampal astrocytes via activating astrocytic NMDA receptor (Figs. 3, 4), then decreased Lrp4 expression level in hippocampal astrocytes (Figs. 1, 2). Locally reduction of Lrp4 expression level in hippocampus by sh Lrp4 lentivirus trans-infection increased the threshold of seizures of mice (Fig. 5). All these data indicated that hippocampal astrocytes may potentially exert acute anti-seizures actions by increasing ATP release via downregulating Lrp4 expression level through sensing the over released glutamates by seizures. All of above findings supported that as a seizures selfregulation mechanism, astrocytic Lrp4 appears to serve as a negative feedback factor to repress the epileptic condition. It provides a new potential therapeutic target for seizures regulation.

In neuromuscular system, LPR4 is highly expressed regionally, mainly expressed in the areas with high neuronal activity (NMJ, hippocampus). High neuronal activity enhances the expression of many genes to alter structural and functional properties of the brain, such as BDNF, NRG1 [42, 43], and so on. So whether is the regional expression of Lrp4 due to high neuronal activity? On the contrary, our finding is that high neuronal activity induced by seizures rapidly depressed the expression of 
Lrp4, which indicated high neuronal activity is an acute inhibition signal for the expression of Lrp4. Why? It has been well studied that the mechanisms of high AChR concentration at $\mathrm{MNJ}$ is the result of coordination of positive and negative signals. As a negative signal, neuronal activity released ACh suppresses AChR synthesis, transport to the cell membrane, clustering or anchoring, and stability in entire muscle fibers [44, 45]. As the positive signaling, agrin produced by nerve terminals and deposited in synaptic basal lamina promotes the recycling of AChRs, increases their metabolic stability, enhances a vesicle dependent transport of AChRs to the synaptic membrane $[46,47]$. So whether the Lrp4 highly concentrates at NMJ and regional expression of Lrp4 in mice brain are the result of coordination of positive and negative signals, liking $\mathrm{AChR}$ ? We uncovered that glutamate released by high neuronal activity suppressed Lrp4 expression in hippocampal astrocytes through increasing miR-351-5p expression via activating astrocytic NMDA receptor. So it could be proposed that to forming Lrp4 regional expression, a positive signal must be existed which is worthy to further discover.

\section{Conclusions}

In conclusion, our study demonstrated that high released glutamate during seizures induced by pilocarpine decreased the expression of Lrp4 and increased miR351-5p in hippocampal astrocytes via activating astrocytic NMDA receptor. The reduction of Lrp4 expression was the result of increasing miR-351-5p in hippocampal astrocytes. Locally reducing Lrp4 expression in hippocampus increased mice seizures threshold. All above findings indicated that Lrp4 in hippocampal astrocytes serves as a negative feedback factor in seizures.

\section{Methods}

\section{Experimental animals}

Adult male C57/B6 mice were used for experiments. Lrp4-LacZ reporter mice were from KOMP (VG15248). In all studies, at least three pairs of mice from same litters were used. Significant efforts are also made to minimize the total number of animals used while maintaining statistically valid group numbers. Mice were group-housed in ventilated cages (no more than 5 per cage) in a temperature-controlled room with a 12-h light/dark cycle. Mice had access to water and rodent chow diet ad libitum. All experiments with animals were approved by the Institutional Animal Care and Use Committee of Nanchang University.

\section{Status epilepticus (SE) induction}

Pilocarpine induced SE model as described previously [19]. Adult C57/B6 mice (8-12 weeks) were injected with scopolamine $(2 \mathrm{mg} / \mathrm{kg}$, i.p.) to block peripheral side effects. 30 min later, mice were injected with pilocarpine in $0.9 \%$ saline $(300 \mathrm{mg} / \mathrm{kg}$, i.p.) or $0.9 \%$ saline (same volumes). At different time points, the hippocampus was removed from pilocarpine injected mice which developed status epilepticus or $0.9 \%$ saline injected control mice for RNA and protein extraction.

\section{Primary astrocyte culture}

Hippocampal astrocytes were cultured as described previously with modification [16]. Briefly, hippocampus was dissociated from P3 C57/B6 mice, and digested in HBSS containing $0.1 \%$ trypsin for $10-15$ min. Cells were seeded on poly-L-lysine-coated $100 \mathrm{~mm}$ culture dishes at high density $\left(1 \times 10^{7} /\right.$ dish) in culture solution (DMEM medium with $10 \% \mathrm{FBS}, 1 \mathrm{IU} / \mathrm{ml}$ penicillin, and $100 \mathrm{~g} / \mathrm{ml}$ streptomycin). Every 3 days, after shacked extensively to remove oligodendrocytes, microglia, and neurons, medium of each dishes were changed to new culture solution. At DIV 10, 90\% glia cells were GFAP-positive astrocytes. Astrocytes were trypsinized and distributed. When cell confluence quantification reached proper density, astrocytes were treated with different time intervals.

\section{RNA isolation, reverse transcription, and quantitative real time PCR}

For RNA isolation, $1 \mathrm{ml}$ Trizol LS Reagent (Invitrogen, USA) was added to mouse hippocampus tissues, primary hippocampal astrocytes. After an addition of $200 \mu \mathrm{l}$ chloroform, RNA was precipitated with isopropyl alcohol. After washed with $75 \%$ ethanol, RNA was dissolved in RNase free water. The concentration and purity of RNA were determined at 260/280 $\mathrm{nm}$ using a nanodrop spectrophotometer (Thermo Fisher Scientific, Wilmington, DE, USA). Reverse transcription of mRNA was performed using a Fermentas reverse transcriptase system. Total RNA were reverse-transcribed into cDNA using oligo dT primers. PCR primers were designed using the Universal Probe Library of Roche on the basis of the reported mRNA sequences. The primers used in qRT PCR are listed as follows: Lrp4 F: 5'-GTGTGGCAGAAC CTTGACAGTC-3', R: 5'-TACGGTCTGAGCCATCCA TTCC-3'; Gapdh F: 5'-GAGGGCATGGGTCAGAAG -3', R: 5'-GAGGCGTACAGGGATAGCAC-3'. Quantitative real time PCR was measured using a Thermo Scientific Maxima SYBR Green/ROX qPCR Master Mix $(2 \times)$ (Cat. K0221) following the procedures laid out by the manufacturer. qPCR was run on a Roche Lightcycler 480 (Roche Applied Science, Basel, Switzerland), according to the instructions of the manufacturer. Data analysis was performed with the software provided by the manufacturer. Quantitation cycle $(\mathrm{Cq})$ values were normalized to Gapdh, which was used as an internal control. 


\section{Stem-loop micro-RNA RT-qPCR}

micro-RNA expression was analyzed using Stem-loop micro-RNA RT-qPCR assay. Stem-loop micro-RNA RT and qPCR primers were listed in support information Table 1. cDNA was generated by reverse transcription using $1 \mu \mathrm{g}$ RNA as template. Stem-loop micro-RNA RT primers were combined to transcribe the total RNA. qPCR was performed using the Thermo Scientific Maxima SYBR Green/ROX qPCR Master Mix $(2 \times)$ (Cat. K0221) and run on a Roche Lightcycler 480 (Roche Applied Science, Basel, Switzerland), following the manufacturer's protocol and instructions. Data analysis was performed with the software provided by the manufacturer. Quantitation cycle $(\mathrm{Cq})$ values were normalized to U6 small nuclear RNA, which was used as an internal control.

\section{In situ X-gal assay}

After quickly isolated and embedded in OCT (TissueTek), mice brains were cut at $40-\mu \mathrm{m}$ interval by coronal sections and every fourth section was collected and mounted on slides. Brain sections were fixed for $4 \mathrm{~min}$ in ice cold X-gal fixative solution $(2 \mathrm{mM} \mathrm{MgCl}, 5 \mathrm{mM}$ EGTA with $0.2 \%$ glutaraldehyde in PBS). After being washed in PBS 3 times, brain sections were stained in X-gal staining solution $(1 \mathrm{mg} / \mathrm{ml} \mathrm{X}$-gal, $5 \mathrm{mM} \mathrm{K}$ $3 \mathrm{Fe}(\mathrm{CN})_{6}, 5 \mathrm{mM} \mathrm{K}_{4} \mathrm{Fe}(\mathrm{CN})_{6}, 0.02 \% \mathrm{NP}-40,0.01 \%$ deoxycholate, and $2 \mathrm{mM} \mathrm{MgCl}$ in PBS) at $37{ }^{\circ} \mathrm{C}$ for $8 \mathrm{~h}$. And after being washed in PBS 3 more times, brain sections were counterstained with nuclear Fast Red (Vector Labs, H-3403).

\section{Western blotting}

Hippocampus and cultured astrocytes were homogenized and prepared in RIPA Buffer containing $(50 \mathrm{mM}$ Tris-HCl pH 7.4, $150 \mathrm{mM} \mathrm{NaCl}, 2 \mathrm{mM}$ EDTA, $1 \mathrm{mM}$ PMSF, $50 \mathrm{mM}$ sodium fluoride, $1 \mathrm{mM}$ sodium vanadate, $1 \%$ sodium deoxycholate, $1 \%$ SDS and $1 \%$ protease inhibitors cocktails). Samples were resolved on SDS/PAGE, and transferred to nitrocellulose membranes. Then the membranes were incubated in TBST buffer $(100 \mathrm{mM}$ Tris$\mathrm{HCl} \mathrm{pH} \mathrm{7.4,} 150 \mathrm{mM} \mathrm{NaCl}, 0.1 \%$ Tween-20) with $5 \%$ skim milk at RT for $1 \mathrm{~h}$. After being washed 3 times with TBST buffer, the membranes were incubated in primary antibody overnight at $4{ }^{\circ} \mathrm{C}$. And being washed 3 more times with TBST buffer, the membranes were incubated with HRP-conjugated secondary antibody (Life Technology) in the same TBST buffer with 5\% skim milk at RT for $1 \mathrm{~h}$. Immunoreactive bands were visualized using enhanced chemiluminescence (Pierce). Band density of interested proteins was normalized in relation to loading control.

\section{Transfections of microRNA mimics and inhibitors}

Transfections of microRNA mimics and inhibitors were conducted using Lipofectamine3000 (Invitrogen), following the procedures laid out by the manufacturer. Cells were plated in six-well plates or $100 \mathrm{~mm}$ culture dishes. miR-351-5p mimics (50 nM, Ribobio, Guangzhou, China); miR-351-5p inhibitors (50 nM, Ribobio, Guangzhou, China); and controls including miR-34b-5p $\mathrm{m} \mathrm{NC}$, miR-34b-5p I NC were transfected into primary astrocytes when they reached $60-70 \%$ confluence. Transfection efficiency was found to be around $80 \%$ by flow cytometry.

Table 1 Stem-loop RT and RT-quantitative polymerase chain reaction primer sequences

\begin{tabular}{ll}
\hline Gene & Sequence $\left(\mathbf{5}^{\prime} \boldsymbol{\rightarrow} \mathbf{3}^{\prime} \mathbf{)}\right.$ \\
\hline U6 (F) & CTCGCTTCGGCAGCACA \\
U6 (R) & AACGCTTCACGAATTTGCGT \\
mmu-miR-125a-5p (RT) & GTCGTATCCAGTGCAGGGTCGAGGTATTCGCACTGGATACGACTCACAGGT \\
mmu-miR-351-5p (RT) & GTCGTATCCAGTGCAGGGTCCAGGTATTCGCACTGGATACGACCAGGCTCA \\
mmu-miR-6367 (RT) & GTCGTATCCAGTGCAGGGTCGAGGTATTCGCACTGGATACGACTCCTGAAC \\
mmu-miR-125b-5p (RT) & GTCGTATCCAGTGCAGGGTCCGGGTATTCGCACTGGATACGACTCACAAGT \\
mmu-miR-6394 (RT) & GTCGTATCCAGTGCAGGGTCCGAGTATTCGCACTGGATACGACAGACCTGG \\
mmu-miR-125a-5p (F) & CGCGTTCCCTGAGACCCTTTA \\
mmu-miR-351-5p (F) & CGTTCCCTGAGGAGCCCTT \\
mmu-miR-6367 (F) & AGCGTTCCCTGAGACCCTG \\
mmu-miR-125b-5p (F) & CGCGTTCCCTGAGACCCTA \\
mmu-miR-6394 (F) & AGCGTTCCCTGAGTGGGG \\
General mmu-miR (R) & ATCCAGTGCAGGGTCCGAGG \\
\hline
\end{tabular}




\section{Construction of the lentivirus}

The optimal sequence of small interfering RNAs against mouse Lrp4 (5'-GCAGTGTGATGGAGACAAT-3') was cloned into the plasmid pll3.7-GFP, which encodes a human immunodeficiency virus (HIV)-derived lentiviral vector containing a multiple cloning site for the insertion of shRNA constructs to be driven by an upstream U6 promoter and a downstream cytomegalovirus promoter-GFP (marker gene) cassette flanked by loxP sites. The scrambled shRNA plasmid was constructed by a similar process (5'-GGATGACAGCGTTAGAGTA-3'). These modified plasmids were further co-transfected into HEK293T cells with lentiviral packaging plasmids to generate $\operatorname{Lrp} 4$ shRNA-expressing lentivirus, or scrambled Lrp4 shRNA-expressing lentivirus.

\section{Stereotactic injection}

For stereotactic injection of lentivirus, the C57/B6 mice (7-8 weeks) were anesthetized and stereotaxically injected with a virus into molecules layer (ML) of the hippocampus region $(0.5 \mathrm{ml}$ at $0.25 \mathrm{ml} / \mathrm{min})$ with the following coordinates (posterior $=-1.4 \mathrm{~mm}$ from Bregma, lateral $= \pm 1.4 \mathrm{~mm}$, ventral $=1.7 \mathrm{~mm}$ ) as previously described [48]. The mice were allowed to recover for 14 days and were handled every other day to reduce the stress associated with handling at the time of behavior testing.

\section{Seizures behavior analysis}

Two weeks after lentivirus injections, 30 min after injection of scopolamine ( $2 \mathrm{mg} / \mathrm{kg}$, i.p.), mice were injected with pilocarpine $(200 \mathrm{mg} / \mathrm{kg}$, i.p.), and followed with additional injections of pilocarpine $(100 \mathrm{mg} / \mathrm{kg})$ every $30 \mathrm{~min}$. Behavioral seizures were scored based on the criteria: stage 0 , no seizure; stage 1 , head nodding; stage 2 , sporadic full-body shaking, spasms; stage 3 , chronic fullbody spasms; stage 4, jumping, shrieking, falling over; stage 5 , violent convulsions, falling over, death. To detect seizure onset latency, pentylenetetrazol (PTZ, $50 \mathrm{mg} / \mathrm{kg}$, i.p.) were injected into mice, then the time of the onset of generalized convulsive seizures (GS) were recorded.

\section{Statistical analysis}

Statistical analysis was done using the GraphPad Prism version 6.01 (GraphPad Software). All data in each group were presented as mean with SD (standard deviation). Two-tailed student t-test was used to compare data from each group. $P<0.05$ was considered to be statistically significant.

\section{Supplementary information}

Supplementary information accompanies this paper at https://doi. org/10.1186/s13578-020-00498-w.

Additional file 1: Figure S1. Seizures increased $B d n f$ mRNA in vivo and glutamate increased $B d n f$ mRNA in vitro. $A$, in vivo, relative mRNA level of $B d n f$ in hippocampus increased after pilocarpine injection, which were collected at different time point ( 0 h, 2 h, 4 h, 12 h) after injection. B, in vitro, relative mRNA level of $B d n f$ in cultured astrocytes increased after glutamate treating, which were collected at different time point $(0 \mathrm{~h}, 2 \mathrm{~h}$, $4 \mathrm{~h}, 12 \mathrm{~h}$ ) after treatment. For each experiment, three separate experiments performed in duplicate $\left(^{* *} p<0.01\right)$.

\section{Abbreviations}

Lrp4: Low-density lipoprotein receptor-related protein 4; LDLR: Low-density lipoprotein receptor; BDNF: Brain-derived neurotrophic factor; LMol: Lacunosum-moleculare layer; Mol: Molecules layer; NMDA: N-Methyl-D-aspartate; AP5: DL-2-amino-5-phsphonovaleic acid; PTZ: Pentylenetetrazol; NMJ: Neuromuscular junction; SE: Status epilepticus; shRNA: Short hairpin ribonucleic acid; GS: Generalized convulsive seizures.

\section{Acknowledgements}

Not applicable.

\section{Authors' contributions}

$Z Y, M Z$ and $Y Y$ performed the experiment; SL conceived and designed the research; $Z Y, M Z$ and $S L$ contributed to make the table and figure; $B L$, and $H J$ contributed to the statistical analysis; $Z Y$ wrote the paper; YY modified English mistakes; SW and SL revised the paper. All authors read and approved the final manuscript.

\section{Funding}

This work was supported in part by grants from the National Natural Science Foundation of China (31671476 to Shiwen Luo), and National Natural Science Foundation of China (31460260 to Shunqi Wang).

\section{Availability of data and materials}

The datasets used and/or analyzed during the current study are available from the corresponding author on reasonable request.

\section{Ethics approval and consent to participate}

This animal protocols in this study were approved by Nanchang University Medical Sciences Committee (China) for research in vertebrate animal, in accordance with EN Directive 2010/63/EU on the protection of animals used for scientific purposes.

\section{Consent for publication}

Not applicable.

\section{Competing interests}

The authors declare that they have no competing interests.

\section{Author details}

${ }_{1}^{1}$ Center for Experimental Medicine, The First Affiliated Hospital of Nanchang University, Nanchang 330006, Jiangxi, China. ${ }^{2}$ Institute of Life Science and School of Life Sciences, Nanchang University, Nanchang 330006, Jiangxi, China. ${ }^{3}$ Nanchang University Hospital, Nanchang University, Nanchang 330006, Jiangxi, China. ${ }^{4}$ Teensen Genesis School, Nanchang 330006, Jiangxi, China. ${ }^{5}$ Jiangxi Key Laboratory of Molecular Diagnostics and Precision Medicine, 17 Yongwai Street, Donghuo Distinct, Nanchang 330006, Jiangxi, China.

Received: 7 October 2020 Accepted: 11 November 2020 Published online: 23 November 2020 


\section{References}

1. Saxena S, Li S. Defeating epilepsy: a global public health commitment Epilepsia Open. 2017;2:153-5

2. Fisher RS, Acevedo C, Arzimanoglou A, Bogacz A, Cross JH, Elger CE, et al. ILAE official report: a practical clinical definition of epilepsy. Epilepsia. 2014;55:475-82

3. Devinsky O, Spruill T, Thurman D, Friedman D. Recognizing and preventing epilepsy-related mortality: a call for action. Neurology. 2016:86:779-86.

4. Duncan JS, Sander JW, Sisodiya SM, Walker MC. Adult epilepsy. Lancet. 2006:367:1087-100

5. Tian N, Boring M, Kobau R, Zack MM, Croft JB. Active epilepsy and seizure control in adults_-United States, 2013 and 2015. MMWR Morb Mortal Wkly Rep. 2018;67:437-42.

6. Z Zhang B, Luo SW, Wang Q, Suzuki T, Xiong WC, Mei L. LRP4 serves as a coreceptor of agrin. Neuron. 2008;60:285-97.

7. Pohlkamp T, Durakoglugil M, Lane-Donovan C, Xian X, Johnson EB, Hammer RE, et al. Lrp4 domains differentially regulate limb/brain development and synaptic plasticity. PLoS ONE. 2015;10:e0116701.

8. Sun XD, Li L, Liu F, Huang ZH, Bean JC, Jiao HF, et al. Lrp4 in astrocytes modulates glutamatergic transmission. Nat Neurosci. 2016;19:1010-8.

9. Choi HY, Dieckmann M, Herz J, Niemeier A. Lrp4, a novel receptor for Dickkopf 1 and sclerostin, is expressed by osteoblasts and regulates bone growth and turnover in vivo. PLoS ONE. 2009;4(11):e7930.

10. Leupin O, Piters E, Halleux C, Hu S, Kramer I, Morvan F, et al. Bone overgrowth-associated mutations in the LRP4 gene impair sclerostin facilitator function. J Biol Chem. 2011:286:19489-500.

11. Xiong L, Jung JU, Wu HT, Xia WF, Pan JX, Shen CY, et al. Lrp4 in osteoblasts suppresses bone formation and promotes osteoclastogenesis and bone resorption. Proc Natl Acad Sci USA. 2015;112:3487-92.

12. Ahn Y, Sims C, Logue JM, Weatherbee SD, Krumlauf R. Lrp4 and wise interplay controls the formation and patterning of mammary and other skin appendage placodes by modulating Wnt signaling. Development. 2013;140:583-93.

13. Tanahashi H, Tian QB, Hara Y, Sakagami H, Endo S, Suzuki T. Polyhydramnios in Lrp4 knockout mice with bilateral kidney agenesis: defects in the pathways of amniotic fluid clearance. Sci Rep. 2016;6:20241.

14. Li L, Xiong WC, Mei L. Neuromuscular junction formation, aging, and disorders. Annu Rev Physiol. 2018;80:159-88.

15. Eilam R, Pinkas-Kramarski R, Ratzkin BJ, Segal M, Yarden Y. Activitydependent regulation of Neu differentiation factor/neuregulin expression in rat brain. Proc Natl Acad Sci USA. 1998:95:1888-93.

16. Liu X, Bates R, Yin DM, Shen C, Wang F, Su N, et al. Specific regulation of NRG1 isoform expression by neuronal activity. J Neurosci. 2011;31:8491-501.

17. Cavalheiro EA. The pilocarpine model of epilepsy. Ital J Neurol Sci. 1995;16:33-7

18. Alachkar A, Azimullah S, Ojha SK, Beiram R, Lazewska D, Kiec-Kononowicz $\mathrm{K}$, et al. The neuroprotective effects of histamine $\mathrm{H} 3$ receptor antagonist E177 on pilocarpine-induced status epilepticus in rats. Molecules. 2019;24:4106.

19. Curia G, Longo D, Biagini G, Jones RS, Avoli M. The pilocarpine model of temporal lobe epilepsy. J Neurosci Methods. 2008;172:143-57.

20. Biagini G, Avoli M, Marcinkiewicz J, Marcinkiewicz M. Brain-derived neurotrophic factor superinduction parallels anti-epileptic-neuroprotective treatment in the pilocarpine epilepsy model. J Neurochem. 2001;76:1814-22

21. Baj G, Del Turco D, Schlaudraff J, Torelli L, Deller T, Tongiorgi E. Regulation of the spatial code for BDNF mRNA isoforms in the rat hippocampus following pilocarpine-treatment: a systematic analysis using laser microdis section and quantitative real-time PCR. Hippocampus. 2013;23:413-23.

22. Smolders I, Khan GM, Manil J, Ebinger G, Michotte Y. NMDA receptormediated pilocarpine-induced seizures: characterization in freely moving rats by microdialysis. Br J Pharmacol. 1997:121:1171-9.

23. Costa MS, Rocha JB, Perosa SR, Cavalheiro EA, Naffah-Mazzacoratti MG. Pilocarpine-induced status epilepticus increases glutamate release in rat hippocampal synaptosomes. Neurosci Lett. 2004;356:41-4.
24. Wu H, Friedman WJ, Dreyfus CF. Differential regulation of neurotrophin expression in basal forebrain astrocytes by neuronal signals. J Neurosci Res. 2004:76:76-85.

25. Lee RC, Feinbaum RL, Ambros V. The C-elegans heterochronic gene Lin-4 encodes small RNAs with antisense complementarity to Lin-14. Cell. 1993;75:843-54.

26. Bartel DP. MicroRNAs: target recognition and regulatory functions. Cell. 2009;136:215-33.

27. Gorter JA, lyer A, White I, Colzi A, van Vliet EA, Sisodiya S, et al. Hippocampal subregion-specific microRNA expression during epileptogenesis in experimental temporal lobe epilepsy. Neurobiol Dis. 2014;62:508-20.

28. Zhang B, Tzartos JS, Belimezi M, Ragheb S, Bealmear B, Lewis RA, et al. Autoantibodies to lipoprotein-related protein 4 in patients with doubleseronegative myasthenia gravis. Arch Neurol. 2012;69:445-51.

29. Shen C, Lu Y, Zhang B, Figueiredo D, Bean J, Jung J, et al. Antibodies against low-density lipoprotein receptor-related protein 4 induce myasthenia gravis. J Clin Invest. 2013;123:5190-202.

30. Fisher RS, van Emde BW, Blume W, Elger C, Genton P, Lee P, et al. Epileptic seizures and epilepsy: definitions proposed by the International League Against Epilepsy (ILAE) and the International Bureau for Epilepsy (IBE). Epilepsia. 2005;46:470-2.

31. Cho KO, Lybrand ZR, Ito N, Brulet R, Tafacory F, Zhang L, et al. Aberrant hippocampal neurogenesis contributes to epilepsy and associated cognitive decline. Nat Commun. 2015;6:6606.

32. Vezzani A, Baram TZ. New roles for interleukin-1 Beta in the mechanisms of epilepsy. Epilepsy Curr. 2007;7:45-50.

33. Heinemann U, Kaufer D, Friedman A. Blood-brain barrier dysfunction, TGFbeta signaling, and astrocyte dysfunction in epilepsy. Glia. 2012:60:1251-7.

34. Oyrer J, Maljevic S, Scheffer IE, Berkovic SF, Petrou S, Reid CA. Ion channels in genetic epilepsy: from genes and mechanisms to disease-targeted therapies. Pharmacol Rev. 2018;70:142-73.

35. Fukata Y, Fukata M. Epilepsy and synaptic proteins. Curr Opin Neurobiol. 2017:45:1-8.

36. Binder DK, Croll SD, Gall CM, Scharfman HE. BDNF and epilepsy: too much of a good thing? Trends Neurosci. 2001;24:47-53.

37. Liu G, Gu B, He XP, Joshi RB, Wackerle HD, Rodriguiz RM, et al. Transient inhibition of TrkB kinase after status epilepticus prevents development of temporal lobe epilepsy. Neuron. 2013;79:31-8.

38. Pun RYK, Rolle IJ, LaSarge CL, Hosford BE, Rosen JM, Uhl JD, et al. Excessive activation of mTOR in postnatally generated granule cells is sufficient to cause epilepsy. Neuron. 2012;75:1022-34.

39. Woo RS, Li XM, Tao Y, Carpenter-Hyland E, Huang YZ, Weber J, et al. Neuregulin-1 enhances depolarization-induced GABA release. Neuron. 2007;54:599-610.

40. Patel DC, Tewari BP, Chaunsali L, Sontheimer H. Neuron-glia interactions in the pathophysiology of epilepsy. Nat Rev Neurosci. 2019;20:282-97.

41. Boison D. The adenosine kinase hypothesis of epileptogenesis. Prog Neurobiol. 2008:84:249-62.

42. Ernfors P, Bengzon J, Kokaia Z, Persson H, Lindvall O. Increased levels of messenger RNAs for neurotrophic factors in the brain during kindling epileptogenesis. Neuron. 1991;7:165-76.

43. Tan GH, Liu YY, Hu XL, Yin DM, Mei L, Xiong ZQ. Neuregulin 1 represses limbic epileptogenesis through ErbB4 in parvalbumin-expressing interneurons. Nat Neurosci. 2012;15:258-66.

44. Wu H, Xiong WC, Mei L. To build a synapse: signaling pathways in neuromuscular junction assembly. Development. 2010;137:1017-33.

45. Mohseni P, Sung HK, Murphy AJ, Laliberte CL, Pallari HM, Henkelman M, et al. Nestin is not essential for development of the CNS but required for dispersion of acetylcholine receptor clusters at the area of neuromuscular junctions. J Neurosci. 2011;31:11547-52.

46. Brenner HR, Akaaboune M. Recycling of acetylcholine receptors at ectopic postsynaptic clusters induced by exogenous agrin in living rats. Dev Biol. 2014:394:122-8.

47. Basu S, Sladecek S, Martinez de la Pena y Valenzuela I, Akaaboune M, Smal I, Martin K, et al. CLASP2-dependent microtubule capture at the 
neuromuscular junction membrane requires LL5beta and actin for focal delivery of acetylcholine receptor vesicles. Mol Biol Cell. 2015;26:938-51.

48. Zhang H, Sathyamurthy A, Liu F, Li L, Zhang L, Dong Z, et al. Agrin-Lrp4Ror2 signaling regulates adult hippocampal neurogenesis in mice. Elife. 2019;8:e45303.

\section{Publisher's Note}

Springer Nature remains neutral with regard to jurisdictional claims in published maps and institutional affiliations.
Ready to submit your research? Choose BMC and benefit from:

- fast, convenient online submission

- thorough peer review by experienced researchers in your field

- rapid publication on acceptance

- support for research data, including large and complex data types

- gold Open Access which fosters wider collaboration and increased citations

- maximum visibility for your research: over $100 \mathrm{M}$ website views per year

At BMC, research is always in progress.

Learn more biomedcentral.com/submissions 